\title{
El movimiento social 15-M de España y la promoción de la protesta a través de sus vídeos en Youtube $^{1}$
}

\author{
Alex Iván ArÉvalo SALINAS \\ Universitat Jaume I de Castellón \\ aarevalo@uji.es
}

\begin{abstract}
Resumen:
El artículo analiza las estrategias discursivas y el impacto de ocho vídeos que se publicaron en Youtube entre septiembre de 2012 y marzo de 2013 para promocionar las protestas sociales que se desarrollaron en la ciudad de Madrid. Estos vídeos son elaborados por el grupo audiovisual Toma la Tele y difunden las convocatorias organizadas por diferentes colectivos vinculados al movimiento social $15-\mathrm{M}$ en España. Tras el análisis realizado se comprueba que en tres vídeos se utiliza la violencia como estrategia de persuasión.
\end{abstract}

Palabras claves: Movimiento social; 15-M; España; comunicación; protesta; Youtube.

\section{Social movement 15-M in Spain and the promotion of protest through their videos on Youtube}

\begin{abstract}
:
The article analyzes the discursive strategies and the impact of eight videos that are posted on YouTube between September 2012 and March 2013 to promote social protests taking place in the city of Madrid. These videos are made by the group audiovisual Toma la Tele and broadcast the calls organized by different groups linked to the 15-M social movement in Spain. Following the analysis it is found that in three videos using violence as a strategy of persuasion.
\end{abstract}

Key Words: Social Movement; 15-M; Spain; communication; protest; Youtube.

Referencia normalizada:

Arévalo Salinas, A. I. (2014): El movimiento social 15-M de España y la promoción de la protesta a través de sus vídeos en youtube ${ }^{1}$. Historia y Comunicación Social. Vol. 19. Núm. Especial Marzo. Págs. $153-163$

Sumario:1. Introducción. 2. El desarrollo. 2.1 Planteamiento. 2.2 Metodología. 2.3 Análisis. 2.3.1 Plano de identificación. 2.3.2 Plano de contenido. 2.3.3 Plano de recepción. 3. Conclusiones. 4. Referencias bibliográficas. 


\section{Introducción}

Una de las consecuencias del movimiento 15-M, que emergió en mayo de 2011 en España, ha sido la creación de una variedad de proyectos comunicativos que han dado continuidad a los valores y principios que giraron en torno a esta acción colectiva como la participación, la cooperación, el bien común o la solidaridad y, a su vez, han propuesto marcos alternativos de referencia o de contrapoder (García Jiménez, 2013).

Los proyectos comunicativos que se han implementado han surgido tanto en el ámbito online, a partir de las herramientas tecnológicas disponibles y las innovaciones de la web 2.0 a través de páginas web, redes sociales, wikis o blogs, como también en los medios convencionales por intermedio de iniciativas originadas en la prensa escrita y la radio, que han significado un aspecto novedoso en comparación con otros contextos.

Estas experiencias comunicativas pueden clasificarse en dos tipos: las periodísticas y las de creación colectiva del conocimiento. Las periodísticas informan sobre las deliberaciones que se producen en las asambleas de los barrios, dan cobertura informativa a las actividades que organizan los colectivos como impedir los desahucios de las viviendas o bien informan sobre el desarrollo de las protestas, entre otros aspectos. Un ejemplo es el proyecto audiovisual Toma la Tele que se origina en marzo de 2012 y se plantea como un magazine audiovisual de información crítica. Algunos de sus programas son Sí se puede, que relata la actualidad en el ámbito de la vivienda, específicamente los abusos que se producen en este sector, o En Krudo Live, un informativo sobre temas de actualidad de ámbito nacional e internacional que se caracteriza por un enfoque de denuncia. Los programas de Toma la Tele se difunden tanto en su web www.tomalatele.tv como a través de canales de televisión locales de la Comunidad de Madrid como Tele K de Vallecas y canal 33. Como parte de esta categoría también encontramos a la emisora Ágora Sol radio y el periódico mensual Madrid15M, éste último con un tiraje de cerca de 20.000 ediciones impresas. A nivel de ideario, las propuestas periodísticas que han surgido tras el movimiento social 15-M presentan una concepción crítica sobre la calidad de los contenidos de los grandes medios de comunicación. Se señala que algunas de estas empresas han desviado e incumplido su responsabilidad social, y los periodistas su ética profesional, al omitir y tergiversar algunos problemas sociales que generan el sufrimiento de miles de personas. Por su parte, los proyectos definidos como de creación colectiva del conocimiento son aquellas propuestas que fomentan la participación ciudadana y el sentido de conjunto o comunidad, es decir, trasmiten la idea de que todos somos parte y necesarios en una sociedad y que cada opinión cuenta. Estas experiencias abren espacios y brechas de expresión que se encuentran reducidas en el sistema democrático actual. Un proyecto de este tipo es la biblioteca colaborativa Bookcamping (http://bookcamping.cc/), que reseña y enlaza recursos que tienen en su mayoría licencias abiertas. Otro ejemplo es la página $15 \mathrm{M} . c \mathrm{http}: / / \mathrm{www} .15 \mathrm{~m} . \mathrm{cc} /$, que es un recopilatorio de narraciones en torno a las experiencias vividas en el 15-M y que engloba a otra iniciativa como 15Mpedia, 
una enciclopedia libre que define los temas, los conceptos y las prácticas de este movimiento social http://wiki.15m.cc/wiki/Portada Los dos proyectos comunicativos que se describieron anteriormente han aplicado en su organización y, en ocasiones en el enfoque de sus contenidos, algunos de los principios y planteamientos del movimiento 15-M como el asambleísmo (los aspectos importantes se debaten en las asambleas), la deliberación (Es necesario crear espacios de participación y debate) y la horizontalidad (no existen jerarquías y todas las voces cuentan).

La comunicación del movimiento 15-M ha sido un tema que se ha estudiado desde diferentes líneas de análisis. Por ejemplo, se detectan investigaciones que indagan en la construcción mediática de este movimiento social en diarios españoles durante el año 2011 (Pinilla, 2011; Chavero, 2012; Castillo, García y Smolak, 2013). También se registran trabajos que analizan el impacto y la influencia de las redes sociales en el origen, el desarrollo y la visibilidad de esta acción colectiva, siendo más frecuentes los trabajos que investigan Facebook (Piñeiro y Costa, 2012) y Twitter (Chavero, 2012). A lo anterior se añaden investigaciones discursivas sobre los lemas del movimiento (Álvarez, 2013; Martín Corvillo, 2013) o algunas reflexiones teóricas y conceptuales sobre los efectos de las tecnología de la información en la gestación, organización y promoción del 15-M (Barranquero y Calvo, 2013; López, 2013). Al respecto, es importante destacar que algunos de estos artículos han utilizado programas y webs para la recopilación de datos como Addictomatic, Socialmention o Topsy (Castillo, García y Smolak, 2012; Martín Corvillo, 2013).

\section{Desarrollo}

\subsection{Planteamiento}

Para profundizar en las estrategias discursivas de estos proyectos comunicativos, este artículo tomará como caso de estudio los vídeos del grupo audiovisual Toma la Tele, que han sido difundidos en Youtube para promocionar algunas protestas que se organizaron en Madrid durante los años 2012 y 2013, las cuales han sido organizadas por diferentes colectivos que componen o se identifican con el movimiento 15-M. El artículo realiza un análisis de contenido y recepción. El objetivo es retratar las estrategias discursivas para incentivar la participación en estas acciones colectivas $\mathrm{y}$ verificar si estos discursos son coherentes con el ideario del movimiento 15-M en relación a una reivindicación pacífica de sus demandas. A nivel de recepción, se analizarán sus datos cuantitativos para comprobar si estas producciones audiovisuales generaron un espacio de deliberación sobre las problemáticas tratadas. El corpus de estudio lo componen 8 producciones audiovisuales que se difundieron entre septiembre de 2012 y marzo de 2013. Los nombres de estos vídeos, sus fechas de publicación y sus enlaces se registran a continuación: 
- Merkel go home.

Fecha de publicación: 3 de septiembre de 2013

Enlace: http://www.youtube.com/watch?v=UxKACQ5YgYU

- Desmontando Mentiras.

Fecha de publicación: 19 de septiembre de 2012

Enlace: http://www.youtube.com/watch?v=_ClsT8M5d_w

- 7 de octubre: recogida de firmas ILP

Fecha de publicación: 1 de octubre de 2012

Enlace: http://www.youtube.com/watch?v=sUlxB6Jok10

- Sábado 13 de Octubre. Global Noise.

Fecha de publicación: 9 de octubre de 2012

Enlace: http://www.youtube.com/watch?v=W7EqsgIxG6M

- $\quad 14 \mathrm{~N}$ Huelga General.

Fecha de publicación: 12 de noviembre de 2012

Enlace: http://www.youtube.com/watch?v=5_xUnZs5b4U

- ¡Eurovegas No!

Fecha de publicación: 22 de enero de 2013

Enlace: http://www.youtube.com/watch?v=MyrjJKpZXfA

- Promo manifestación PAH 16 de febrero.

Fecha de publicación: 15 de febrero de 2013

Enlace: http://www.youtube.com/watch?v=rTCoZImHEQ4

- UniEnlaCalle

Fecha de publicación: 5 de marzo de 2013

Enlace: http://www.youtube.com/watch?v=b95d5k_BOjY

La pertinencia de este artículo se basa en que la mayoría de las investigaciones sobre el movimiento social 15-M se han centrado en analizar los discursos, la participación y la recepción en redes sociales como Facebook y Twitter. Por ende, existe un espacio para explorar otros ámbitos de difusión como Youtube. Esta plataforma ha sido relevante en la promoción y la sensibilización de los temas de los movimientos sociales al permitir almacenar y propagar discursos audiovisuales sin coste, una característica que favorece la implementación de campañas comunicativas. También estos vídeos trascienden del espacio de Youtube para ser anexados en otras vías y soportes como redes sociales, blogs o páginas web. Los colectivos que conforman el movimiento social 15-M han utilizado el soporte audiovisual como material complementario a sus planteamientos. Piñeiro y Costa señalan que el 57.31 por ciento de las publicaciones que se registran en la cuenta de Facebook del colectivo Democracia Real Ya añaden al texto escrito otros enlaces y recursos. De este porcentaje, un 16.4 por ciento corresponde a los vídeos de Youtube (Piñeiro y Costa, 2012: 99). La inclusión de los vídeos como material complementario también lo registra Castillo, García y Smolak (2013: 80-82), quienes concluyeron que Youtube fue la tercera fuente de 
información más utilizada en el sitio web de Indignados, la cuarta en 15-M y la quinta en Acampada Sol.

\subsection{Metodología}

La metodología de este artículo se plantea desde el siguiente esquema:

Plano de identificación. Se compone de los siguientes ámbitos:

- Fecha de emisión. Se analiza la frecuencia mensual de su emisión.

- Duración. Se mide el promedio de duración en minutos y segundos.

En el caso de que exista un corpus compuesto por diferentes emisores, una investigación más amplia puede incluir el análisis de sus canales de Youtube recopilando datos en tres ámbitos. El primero, lo defino como identificación y son datos básicos como la fecha de creación de la cuenta, el sexo, el nombre o tipo de imagen del perfil. El segundo ámbito es la actividad y la participación incluye aspectos como el análisis del número de vídeos publicados en un tiempo determinado, el tipo de contenidos de estas producciones, el análisis de sus comentarios a nivel cuantitativo y cualitativo. Por último, el tercer ámbito es la recepción y mide el impacto de estos canales a través del número comentarios que recibe como también su análisis, el promedio de reproducciones, la cantidad de suscripciones, los vídeos compartidos y las calificaciones en Me gusta o No me gusta. Estos datos también pueden servir para investigar las cuentas de Youtube de las personas que comentan los vídeos de los movimientos sociales para detallar un perfil sobre su actividad y su relación con el activismo. De esta manera, se puede verificar si las personas que emiten estos comentarios reproducen en sus canales estos contenidos o temáticas afines. A partir del concepto de eficacia cultural (Pinazo y Nos, 2013), en este artículo se considera que una producción tendrá mayor impacto cuando logra implicar en el debate a personas que no tienen un perfil de activista en la red de Youtube. Sin embargo, para un análisis más profundo es pertinente realizar entrevistas a estos ciudadanos.

Plano de contenido. En este ámbito se realiza un análisis de las estrategias discursivas y sus modos de difusión a partir de los siguientes ámbitos:

- Descripción del vídeo. Indaga en los antecedentes que se incluyen en el apartado de información básica. Además de la inserción de las redes sociales.

- Estrategias discursivas: Se estudia las estrategias discursivas para representar al Otro, si se atribuyen responsabilidades a los actores y grupos en la generación de una situación de injusticia y violencia que motiva la organización de una protesta, la incorporación de lemas y sus enfoques. También se comprueba la existencia de violencia cultural (Galtung, 1998) en sus discursos para verificar su coherencia con los principios de reivindicación pacífica del movimiento $15-\mathrm{M}$.

- Aspectos sonoros. Se analiza la coherencia entre la música, los sonidos y las melodías con el contenido temático de los vídeos. 
- Marco de referencia. Se indaga en la cantidad de vídeos que incluyen datos de referencia que permiten situar y entender algunas de las informaciones que se denuncian. También la mención que hacen de las redes sociales y las páginas web.

Plano de recepción. En este ámbito se analiza la información estadística que proporciona Youtube paras realizar comparaciones. Se acceden a datos como:

- Número de reproducciones.

- Cantidad de comentarios.

- Cantidad de Me gusta o No me gusta

- Número de veces que los vídeos son compartidos

- Cantidad de suscripciones.

- Análisis de los comentarios. Algunas categorías que se utilizan en este apartado se recopilan del manual de codificación del equipo de investigación Ciberdemocracia de la Universidad Rey Juan Carlos de Madrid, y que es recogido por Iranzo y Farné (2013). Al respecto, se evalúan datos como la longitud del mensaje: Corto (menos de 140 caracteres), Medio (entre $140 \mathrm{y}$ $500)$ y Largo (más de 500). El posicionamiento de los comentarios en categorías como: Negativo (Contrario al contenido), Sin posicionamiento (No da a entender de manera clara su opinión) y Positivo (Favorable al contenido). El nivel argumentativo: Simple (Se centra en la descripción), Medio (Se argumenta sin abordar el contexto y la estructura) y Elaborado (Se aportan datos, se menciona el contexto y los temas de fondo).

\subsection{Análisis}

A continuación se presentan los principales resultados del análisis comparativo realizado a los ocho vídeos publicados entre septiembre de 2012 y marzo de 2013.

\subsubsection{Plano de identificación}

El promedio de duración de los vídeos es de 51.75 segundos, en tres de ellos se iguala o supera el minuto. En los meses de septiembre y octubre de 2012 se publicaron dos vídeos por mes mientras que en diciembre no se registraron emisiones.

\subsubsection{Plano de contenido}

- Descripción del vídeo: Todas las piezas audiovisuales incorporan información en la sección de descripción, aunque ésta varía de acuerdo a los datos aportados. En tres de los ocho videos que componen el corpus se incluyen contenidos de referencia que favorecen el conocimiento sobre los motivos y los problemas de fondo que originan las protestas. En Merkel go home se señala que se producirá un encuentro entre Mariano Rajoy y empresarios alemanes y 
que el Consejo de Gobierno dará detalles sobre el rescate financiero a España dictado por el Banco Central Europeo. En el vídeo denominado 7 de octubre: recogida de firmas ILP se explica la necesidad de participar en una recogida de firmas para presentar una Iniciativa Legislativa Popular, con la finalidad de generar una ley que prohíba los desahucios de viviendas. Para mejorar la comprensión de esta acción ciudadana se da a conocer el número de desahucios producidos en España, 500.000, y para empoderar se visibilizan los éxitos en este campo al mencionar la paralización de estos procedimientos, un total de 400. Por su parte, el vídeo Sábado 13 de Octubre Global Noise opta por incluir enlaces como páginas web, cuentas de Facebook o emails. En los cinco vídeos restantes en la sección de información se aportan datos básicos y breves sobre las convocatorias y sus temas de interés. Por ejemplo, en los vídeos Desmontando Mentiras y Promo Manifestación PAH 16 de febrero se añaden sus respectivos títulos. De los ocho vídeos que componen el corpus, en tres de ellos (14N huelga general, ;Eurovegas No! y 7 de octubre: recogida de firmas $I L P)$ se incorporan palabras o frases que apelan a la implicación y el compromiso como: la huelga es cuestión de todos, ¡No faltes! o el 7 de octubre todas a firmar. Por su parte, en tres de ellos (Merkel go home, UniEnlaCalle y Sábado 13 de Octubre Global Noise) se anexan las redes sociales principalmente la inclusión de hashtag o cuentas de Facebook y twitter.

- b) Estrategias discursivas: A nivel de discurso, la mayor parte de los vídeos no atribuye las responsabilidades a grupos o personas por las injusticias y la violencia que son el desencadenante de una protesta. Del total del corpus, en dos vídeos se culpa a determinados actores por los problemática que se reivindica. En Merkel go home el discurso responsabiliza a la canciller de Alemania, Angela Merkel y al presidente de gobierno de España, Mariano Rajoy. Por su parte, en el vídeo Promo manifestación PAH 16 de febrero la responsabilidad recaen en los bancos, siendo visible en una pancarta que señala Dictadura de los bancos ¡NO! Para incentivar la participación en la convocatoria, aumentar el compromiso y la motivación o bien enfatizar en el rechazo a una determinada situación, las producciones audiovisuales incorporan lemas como ¡Todas a Estudiar!, ¡Toma la calle!, Construyendo Alternativas, No debemos. No pagamos, Si la ley desahucia. ¡Cambiemos la ley!, Si nos roban el futuro. Paramos la ciudad, Lo que pasa en las Vegas iQue se quede en las Vegas!, ¡Sí se Puede!, Stop Desahucios. Cabe destacar que el lema No debemos. No pagamos se repite en dos vídeos. Algunos de estos lemas expresan decisión e intensidad en sus planteamientos en relación a las respuestas que se deben tomar ante una situación considerada injusta. Nos referimos a los lemas Si nos roban el futuro. Paramos la ciudad, No debemos. No pagamos, Si la ley desahucia. Cambiemos la Ley. Estos lemas comienzan con una frase que refleja el escenario injusto para posteriormente proponer una respuesta o una actuación concreta como parar la ciudad, no pagar la deuda o cambiar la ley. En cuatro lemas se responde utilizando el plural para reforzar la idea de conjunto e incentivar la participación como ¡Todas a Estudiar! Otros lemas 
plantean la idea de que el cambio es posible desde una visión positiva como Sí se Puede o Construyendo Alternativas. En tres de vídeos se utiliza la violencia como estrategia de persuasión, aunque en distintos grados de manifestación. El vídeo Merkel go home presenta una construcción negativa del otro, en este caso de la canciller de Alemania, Angela Merkel. La cabeza de esta mandataria es incorporada a un dibujo de una figura humana. En la escena se observa a Merkel volar por los aires tras recibir una patada por parte de otro dibujo de similares características. De forma paralela, se anuncia la frase Merkel go Home. Con esta escena se quiere reiterar que la visita de Angela Merkel no es bienvenida a España, tal como se plasma en el titular del vídeo. Cabe destacar que este vídeo tuvo una segunda reproducción con diferente titulo al día siguiente, que incluyó la frase "Fuck the troika" que expresa una descalificación hacia este grupo conformado por la Comisión Europea, el Banco Central Europeo y el Fondo Monetario Internacional. En otros casos, la violencia es usada como estrategia para magnificar el impacto de los temas que retratan sus discursos. Un ejemplo es ;Eurovegas No!, donde se sensibiliza sobre los efectos negativos de la eventual construcción en Madrid del casino Eurovegas. Para ello se recurre a escenas donde se muestran asesinatos, disparos a escasos metros, rostros mutilados, insectos o incluso cerebros. Esta estrategia discursiva más que propiciar un debate y una reflexión sobre la conveniente de inaugurar un casino de juegos provoca un rechazo al receptor por la crudeza de las imágenes. Una manera más sutil e indirecta de presentar la violencia acontece en $14 \mathrm{~N}$ huelga general. Este vídeo si bien tiene como escenario principal una manifestación pacífica, en la medida que transcurre la reproducción se incluyen recuadros pequeños con imágenes que en algunos casos presentan indicios se confrontación como un objeto que se incendia, una pared pintada con la palabra guerra social o unos encapuchados que mueven un contenedor de basura, aunque en este último caso no se puede observar si su finalidad es crear una barricada. Un enfoque más coherente con los planteamientos de reivindicación pacífica del $15-\mathrm{M}$ se presentan en los vídeos que retratan las demandas de la Plataforma de Afectados por la Hipoteca (PAH). En Promo manifestación PAH 16 de febrero se informa sobre los objetivos y los logros que se han alcanzado con sus actuaciones. La visibilidad de los éxitos concretos es una forma de empoderar porque fomenta emociones positivas como la esperanza en relación a las posibilidades de concretar cambios y reformas sobre las demandas que se exigen. Esto queda patente en la incorporación del lema ¡Si se puede! Por otro lado, en la segunda parte de esta producción audiovisual se visualiza a un grupo de personas que se manifiestan en favor de estas demandas. La inclusión de estas personas puede interpretarse como una forma de mostrar el respaldo existente y valorar la unidad y la participación que genera este colectivo.

- Aspectos sonoros: En relación a los aspectos sonoros, las producciones audiovisuales utilizan principalmente melodías, algunas de ellas de corte futurista (Sábado 13 de Octubre Global Noise, 7 de octubre: recogida de firmas ILP, 
Desmontando mentiras). Otras expresan un ambiente de expectación ( $14 \mathrm{~N}$ huelga general), de intensidad (;Eurovegas No!) o bien generan un estado de calma y de esperanza, que perfectamente podría ser categorizada como música de relajación (Promo Manifestación PAH 16 de febrero). En Merkel go home se recurre a una melodía que está presente en el imaginario colectivo en las culturas occidentales como la canción "Marcha imperial" de la película Guerra de las Galaxias. De los ocho vídeos analizados, solamente Merkel go home incorpora una canción con texto, la cual pertenece al grupo argentino Dama Gratis y se titula "Los dueños del pabellón". Las melodías de corte futuristas que se emiten en tres vídeos no presentan relación con el contenido que se abordan.

La relación más evidente entre los aspectos sonoros y el contenido se produce en el video Merkel go home. Para crear un ambiente amenazante ante la inminente llegada de la canciller de Alemania, Angela Merkel, la producción audiovisual comienza con la frase "Ya están aquí," que se complementa con la canción la "Marcha imperial" de la Guerra de las Galaxias, que en esta película se utiliza para caracterizar a su personaje antagónico, Darth Vader. Desde el segundo 23, se incluye la canción "Los dueños del pabellón" del grupo argentino de cumbia Dama Gratis. Su letra promociona la participación de los ciudadanos en las protestas e incentiva que se exprese este rechazo de manera tajante. Esto se retrata en el siguiente fragmento de esta canción: "Ahora nosotros tomamos el control. Somos los dueños del pabellón. Estamos cansados de tanta represión. Vamos a tocar de esta prisión. Quiero que todos se amotinen".

- Marco de referencia: Al analizar el marco de referencia comprobamos que en solamente tres vídeos (Merkel go home, Promo manifestación PAH 16 de febrero y 7 de octubre: recogida de firmas $I L P$ ) se aportan datos e información sobre los objetivos de las protestas y sus reivindicaciones, un aspecto que contribuye a la comprensión de la temática. Por ejemplo, en Merkel go home la reivindicación se expresa en la frase "Ni un euro más para rescatar a los bancos", que viene precedido del lema "No debemos. No pagamos". Los vídeos de la Plataforma de Afectados por las Hipotecas (PAH) son los que aportan mayor cantidad de datos de referencia. En Promo manifestación PAH 16 de febrero se mencionan los logros alcanzados, en este caso 1.402.854 firmas conseguidas, y los objetivos que se pretenden alcanzar con la acción ciudadana como la dación en pago, la moratoria de desahucios y un parque público de alquiler social. También estos logros se grafican al informar sobre el número de desahucios paralizados, un total de 562. La conexión con las redes sociales se producen en cuatro vídeos, principalmente se hacen referencia a los hashtag de Twitter y en uno de ellos se incluye la página web del movimiento de Afectados por la Hipoteca de Madrid. Cabe destacar que todos los vídeos cierran con la mención a la página web de Toma la Tele. 


\subsubsection{Plano de recepción.}

Los datos para analizar la recepción de los vídeos que componen el corpus de estudio han sido recopilados en octubre de 2012. Este aspecto se recalca debido a la rapidez con que esta información puede cambiar en un contexto digital.

A nivel estadístico, el video que tiene mayor impacto en cuanto al número de reproducciones, la suscripciones generadas, la cantidad de veces compartido, el número de Me gusta y la cantidad de comentarios es Merkel go home. Esta producción audiovisual tiene 5.582 reproducciones, 13 suscripciones, 73 veces compartido, 42 me gusta y 2 comentarios. Cabe destacar, que el número de reproducciones no indica la cantidad de personas que visionaron este vídeo, dado que un solo receptor podría reproducir varias veces un vídeo. El resto presentan un impacto ostensiblemente menor, aspecto que se evidencia en la diferencia entre el número de reproducciones de Merkel go home con 5582 y el que registra la menor cantidad como $14 \mathrm{~N}$ huelga general con 149. La diferencia es de 5433 reproducciones.

El segundo lugar en términos de impacto cuantitativo lo comparten varios vídeos en sus diferentes categorías. Por ejemplo, el vídeo ;Eurovegas No! registra esta posición en el número de reproducciones con 1208. En la cantidad de veces compartido esta categoría corresponde al vídeo Sábado 13 de Octubre Global Noise con 10. Cabe destacar que en las calificaciones en Me gusta o No me gusta los vídeos presentan una tendencia favorable. Solamente se registran cinco votaciones negativas.

Existe una escasa participación a nivel de comentarios si comparamos estos datos con otros contextos y casos (Uldam y Askanius, 2013). De los ocho vídeos analizados se registraron cuatro comentarios distribuidos en tres piezas audiovisuales. Dos de ellos en Merkel go home y uno en ;Eurovegas No! y Sábado 13 de octubre Global Noise.

Los cuatro comentarios presentan un posicionamiento favorable al contenido de los vídeos. Cabe destacar que dos de ellos corresponden a grupos y personas que están vinculados y relacionados con las reivindicaciones del movimiento 15-M como es el caso del movimiento social La Rouche España en el vídeo Merkel go home. Este grupo reivindica un cambio económico, principalmente la necesidad de establecer reglas para reducir la especulación. Tiene una longitud media de 475 caracteres. El nivel argumentativo es elaborado porque aporta datos referenciales al mencionar la ley Glass Steagall que se plantea como una alternativa. El segundo comentario se generó en el vídeo Sábado 13 de Octubre Global Noise, el cual es emitido por una persona que informa la fecha y la hora de la protesta y anima a participar con frases como: Te esperamos o lucha por nuestros derechos. El resto de opiniones no generan un diálogo ni profundizan en la temática, incluso en uno de ellos se responde con una palabra a través de la expresión Buenísimo. 


\section{Conclusiones}

Tras el análisis se concluye que del total del corpus analizado compuesto por ocho vídeos, en dos de ellos se explicitaron las responsabilidades de la violencia estructural (Galtung, 1998) a determinados actores y grupos de interés. De manera más evidente se señala esta responsabilidad en el vídeo Merkel go home, la cual recae en la canciller de Alemania, Angela Merkel y en el presidente del gobierno de España, Mariano Rajoy.

En tres vídeos se detectaron indicios de violencia cultural en su construcción discursiva aunque con distintas intensidades. Este enfoque se contrapone y es incoherente con los principios de reivindicación pacífica que se han planteado desde movimiento social 15-M. Para evitar estas incongruencias entre los planteamientos de los discursos y los principios que se promueven es importante que sus creadores evalúen de manera continua sus propuestas comunicativas desde criterios de eficacia cultural. Para ello es pertinente conocer ejemplos de éxito o buenos prácticas de sensibilización que sirvan de referencia para la construcción de las piezas audiovisuales. El uso de la violencia como estrategia discursiva puede tener efectos contradictorios a los planificados porque legitima el tradicional argumento de los grupos de poder, representado en algunos medios de comunicación convencionales y determinados partidos políticos, que asocia la violencia y la inestabilidad a las actuaciones de los movimientos sociales. Lo anterior se logra cuando el debate se centra en la confrontación, y en los enfrentamientos entre la policía y los manifestantes, para desviar la atención sobre los problemas de fondo y las demandas que se solicitan.

Las producciones audiovisuales analizadas no desarrollan marcos de referencias amplios y profundos. En tres vídeos se contextualiza con información sobre las reivindicaciones, los objetivos y los planteamientos. Ejemplo de ello son las propuestas que difunden los temas de la Plataforma de Afectados por la Hipoteca (PAH). Estos vídeos destacan por su enfoque positivo y empoderador al visibilizar los éxitos concretos alcanzados por este colectivo. Esto incentiva emociones positivas como la esperanza en referencia a las posibilidades de conseguir las demandas que se exigen. Todo ello se resume en la inclusión del lema Sí se Puede.

A nivel de recepción, los vídeos estudiados presentan escaso impacto cuantitativo que se comprueba en la cantidad de comentarios registrados. No se generó un debate y una deliberación amplia sobre los temas que engloban al movimiento 15-M o sobre las demandas que se exigen en las protestas. Del total de vídeos analizados, solamente se registraron cuatro comentarios distribuidos en tres piezas audiovisuales. Dos de estas opiniones fueron emitidas por personas o grupos que están relacionados e implicados con los objetivos de las protestas o bien comparten sus intereses. El vídeo con mayor impacto fue Merkel go home con una diferencia ostensible en sus distintos indicadores. 


\section{Referencias bibliográficas}

ÁLVAREZ, E. (2013). "La creatividad del lenguaje como arma social". En GHEORGHE, P. (ed.) (2013). Diversité et identité Culturelle en Europe. Bucarest: editura Muzeul Literaturii Române. p. 83-94.

BARRANQUERO, A.: CALVO, B. (2013). "Claves para comprender el 15-M: Comunicación, redes sociales y democracia deliberativa". En: Diálogos de la comunicación, ${ }^{\circ}$ 86, Cali: FELAFACS, p. 1-18.

CASTILLO, A.; GARCÍA, D.; SMOLAK, E. (2013). "Movimientos sociales y estrategias de comunicación". En: Revista Estudios sobre el mensaje periodístico, vol. 19, $\mathrm{n}^{\circ}$ 1, Madrid: Universidad Complutense. p. 71-89.

CHAVERO, P. (2012). "Ponencia: De la plaza a las portadas: el 15-M y los medios de comunicación". En: III Congreso Internacional en Gobierno, Administración y Políticas Públicas, Madrid, 27-28 de septiembre. P- 1-23.

GALTUNG, J. (1998). Tras la violencia, 3R: reconstrucción, reconciliación, resolución. Afrontando los efectos visiones e invisibles de la guerra y la violencia. Bilbao: editorial Bakeas.

GARCÍA JIMÉNEZ, L. (2013). "E-social movements y resistencia simbólica. Hacia una teoría de la comunicación y el contrapoder". En: Revista Razón y Palabra, $\mathrm{n}^{\circ}$ 81, Ciudad de México: Instituto Tecnológico de Monterrey.

MARTÍN CORVILLO, J. M. (2013). Tesis doctoral 15M: Análisis de la entropía comunicativa. Valencia: Universidad de Valencia.

IRANZO, A.; FARNÉ, A. (2013). "El discurso de regeneración democrática del 15-M y su interpretación por la prensa española". En ZALLO, R.; CASERO, A. (eds.) (2013): Comunicación y regeneración democrática. Castellón: Universitat Jaume I de Castellón-ULEPICC. p. 329-342.

LÓPEZ, G. (2013). "Del 11M al \#15M. Nuevas tecnologías y movilización social en España”. En: Revista F@ro, n 16, Valparaíso: Facultad de Ciencias Sociales de la Universidad de Playa Ancha.

PINILLA, A. (2011). "La percepción del movimiento 15-M en las ediciones digitales de El Mundo y El País". En: Revista Tejuelo, n 12, Badajoz: Consejería de Educación y Cultura del gobierno de Extremadura, p. 196-217.

PINAZO, D.; NOS ALDÁS, E. (2013). "Developing Moral Sensitivity through protest scenarios in international NGDOs' Communication". En: Journal Communication Research, June 18 (online). London: SAGE.

PIÑEIRO, T.; COSTA, C. (2012): "Ciberactivismo y redes sociales. El uso de Facebook por uno de los colectivos impulsores de la "Spanish revolution", Democracia Real Ya (DRY)". En: Observatorio, Special Issue Networked belonging and networks of Belonging-COST ACTION ISO906, Lisboa: OberCom, p. 165-180.

ULDAM, J. y ASKANIUS, T. (2013). "Online civic cultures: debating climate change activism on Youtube". En: International Journal of Comunication, $\mathrm{n}^{\mathrm{o}} 7$, Los Angeles, Estados Unidos: University of Southern California, p. 1185-1204. 


\section{Notas}

Este artículo es parte de los proyecto CSO 2012-34066 Evaluación e indicadores de sensibilidad moral en la comunicación actual de los movimientos sociales del Ministerio de Economía y Competitividad de España y del proyecto P1 1A 2012-05 De víctimas a indignados: visibilidad mediática, migración de imágenes, espectacularización de los conflictos y procesos de transformación social hacia una cultura de paz de la Universitat Jaume I y la Fundación Caja Castellón-Bancaja.

\section{El autor}

Alex Iván Arévalo Salinas es doctor en Estudios Internacionales de Paz, Conflictos y Desarrollo por la Universitat Jaume I de Castellón. Se desempeña como investigador en el Departamento de Ciencias de la Comunicación y el Instituto Interuniversitario de Desarrollo Social y Paz de la Universitat Jaume I de Castellón. Sus líneas de investigación son la comunicación y los conflictos, la comunicación y la paz, y el análisis de discurso. Ha sido coeditor del libro Migraciones y Cultura de Paz: Educando y comunicando solidaridad publicado el 2012 a través de la editorial Dykinson de Madrid. 